ASSESSMENT OF ENERGY STORAGE CONCEPTS FOR USE

IN PULSED SPACE POWER SYSTEMS*

M. Olszewski and D. G. Morris

Oak Ridge National Laboratory

Oak Ridge, TN 37830

CONF-870804--5

ABSTRACT

DE87 009681

Energy storage can be used to reduce primary power requirements and system mass in pulsed space fower supplies. Power from a small continuous source can charge a store to the energy level needed to satisfy the requirements of the relatively short period of sprint mode service. A second store can absorb reject heat during sprint operation and transfer it to the radiator over the longer non-operational period of the orbit. Thus, the designer can trade off primary power and heat rejection system masses against energy storage system mass.

Preliminary assessments have been completed for thermal energy storage in heat rejection systems as well as for regenerable electrical storage modules in systems having nuclear sources with Rankine power conversion and solar sources with Brayton and Rankine power conversion. Storage technologies considered for the regenerable nodules include flywheels, batteries, fuel cells, superconducting magnets and capacitors. Both source and sink thernal storage were examined for the solar energy based systems.

Benefits derived from incorporating therwal storage in the heat rejection system depend on the storage density and the radiator specific mass. The analysis shows that inclusion of a thermal store results in heat rejection system mass reductions for generation times of up to 1100 seconds.

Results show that the storage system value (mass reduction) increastes with decreasing total generation time. In general, the value is greatest for generation times of 600 seconds or less although mass savings are realized for generation times nearly twice as long. For a total generation time of 500 seconds, incorporating storage in a nuclear Rankine power system results in mass reduction of 50\%. Systen masses similar to the nuclear Rankine are obtainable for solar Rankine and Brayton cycles using regenerable electrical storage nodules. However, a 100-orbit recharge time is required, when the constraint of keeping concentrator areas smaller than $1000 \mathrm{~m}^{2}$ is also imposed.

\title{
INTRODUCTION
}

Sprint mode operation with a space power supply is characterized by the need for relatively high power levels (on the order of 100 to $1000 \mathrm{NWe}$ ) for short periods of time ( 100 to 2000 seconds). Due to the pulsed nature of this application, energy storage devices may be exployed to 
reduce overall power system mass. In addition, storage can be used to time-average component and power system heat refection, thus, accruing further mass savings.

Thermal energy storage (TES) can be employed in the heat source and/or sink system. When used as a heat source, it can complement or replace the primary source (nuclear or solar) in the power production cycle. Since recharging of the thermal energy store can generally occur over a longer period than that required for discharge, the primary thermal source can be downsized and mass savings are possible. Thermal storage at the sink can be employed to reduce radiator size associated with the power supply or other space platform components (e.g. power conditioning devices). This results because storage allows the reject heat (generated during the sprint mode) to be dissipated over longer periods, thus, reducing the heat rejection rate.

Alternatively, energy can be stored in regenerable energy storage modules. These devices store electrical energy produced by the primary power system and later discharge electrical energy to the end use. Because charging takes place over time periods longer than the sprint need, significant reductions in the power level required of the primary system result. Energy storage technologies applicable for use in regenerable storage modules include: flywheels, superconducting nagnets, capacitors, batteries and fuel cells.

\section{HEAT REJECTION SYSTEM THERMAL ENERGY STORAGE}

The value of thermal energy storage (TES) in the prinary power heat refection system was examined. In the temperature range of interest, lithlum hydrida (LIH) was determined to be the storage medium of chofce because of tis high heat of fusion $(2.9 \mathrm{MJ} / \mathrm{kg})$ and superior sensible heat $(6.3, \mathrm{~J} / \mathrm{g}-\mathrm{K}) .,, 2$ To give a measure of the value of the storage component, the mass of the heat rejection system using a radiator plus storage was compared to the mass of the baselirie system using only a radiator. The baseline radiator operates at $1100 \mathrm{~K}$ and is sized to handle the instantaneous load imposed by the sprint power need. With thermal storage, the reject heat is placed into storage during the sprint power generation portion of the orbit; then, during the nonoperational portior of the orbit the stored heat is rejected via radiation.

In the inftial assessment, the mor parameters of interest included: energy storage density, alrimum temperature of the storage medium, sprint operation period and radiator specific mass. The storage density depends upon the configuration of the TES unit and the temerature swing. Using LiH in a direct contact configuration minimizes parasitic mass and produces the highest storage density. Ercapsulated LiH shapes (used in packed bed storage units) require a shell; this results in sone reduction in storage density. Since the maximum storage temerature was fixed at $1100 \mathrm{~K}$, the temperature swing was fixed by the alnimu storage temperature. Variation of the minfmum storage terperature produces two 
opposing effects. As the minimum storage temperature increases, the temperature swing decreases. This decreases the storage density (by decreasing the sensible heat contribution) and increases the required storage mass. However, the average radiator flux increases and this decreases the required radiator area and mass.

The total orbital time was fixed at $6000 \mathrm{~s}$, and the sprint period was varied between 100 and $900 \mathrm{~s}$. As a worst case, it was assumed that the storage unit would be fully recharged within a single orbit. Thus, the time available for recharge varfed between 5900 and $5100 \mathrm{~s}$. The baseline system radiator operates at $1100 \mathrm{~K}$ with a heat $f 1 u x$ of 74.3 $\mathrm{kW} / \mathrm{m}^{2}$. The average heat $\mathrm{flux}$ and storage densities for the storage case are presented in Table 1 .

The general trend in storage benefits is illustrated in Fig. 1 with results for the direct contact configuration using a radiator specific mass of $10 \mathrm{~kg} / \mathrm{m}^{2}$. In this plot, a mass ratio less than unity indicates that thermal storage decreases the overall heat rejection system mass. The generation time at which the mass ratio is equal to unity is defined as the crossover time. As anticipated, the mass savings increase with decreasing generation time. It is also clear that an optimum storage minimum temperature exists in the 500 to $700 \mathrm{~K}$ range.

The parametric assessment results for the direct contact and encapsulated configurations are presented in $F 1$ gs. 2 and 3 , respectively. These plots indicate that the optimum minimum storage temperature range is rather broad. They also indicate that the optimum moves toward a higher temperature as the radiator specific mass increases. As anticipated, the value of storage is highly dependent upon the radiator specific mass. As indicated in Fig. 2, the crossover time for the direct contact configuration increases from 600 to 900 seconds when the radiator specific mass increases from 10 to $20 \mathrm{~kg} / \mathrm{m}^{2}$.

Thif inftial analysis was extended to examine the effect of allowing for multiple orbit recharge (i.e., allowing more than one orbit for the storage unit to reject the stored heat and return to the minimum terperature). In addition, lower orbits were simulated by reducing the total orbit time from $6000 \mathrm{~s}$ to $4500 \mathrm{~s}$. The analysis was performed for the encapsulated configuration using a minimum storage temperature of $700 \mathrm{~K}$. The operational storage density for this unit ${ }^{3}$ is $4 \mathrm{MJ} / \mathrm{kg}$. The results, shown in Fig. 4, indicate that mitiple orbit recharging of the storage media extends, "significantly, the crossover tine. For the 6000-s orbit, the crossover time is increased by almost $40 \%$, when the recharge time increases from one to ten orbits. Increasing the number of recharge orbits also decreases the difference in crossover time attributable to the shorter orbit. When only a single orbit is allowed for recharge, the crossover time for the 4500-s orbit is $10 \%$ shorter than that for the 6000-8 orbit. However, when ten orbits are allowed the difference is only $2 \%$. 
Systems employing regenerable sprint power modules were compared to baseline power systems on a mass basis. The primary power systems included nuclear Rankine, solar Brayton, and solar Rankine concepts. For the solar concepts, TES was also included as a storage option. In the power system model, electricity produced by the primary power system can be stored in the regenerable storage module for use during the sprint mode or (in the non-storage case) it can be used immediately to meet sprint needs. With storage, the power cycle operates in a steadystate mode at a power level well below the required pulse power demand.

Storage Performance

The ideal sprint power energy storage module would have a high specific energy concurrent with a high specific power. These performance characteristics were estimated at two levels (Refs. 4-8). In estimating performance of near term systems, currently avallable components (or those anticipated to be available within several years) were used in a configuration compatible with the sprint need. The longer term estimates were based on research goals. With near term technology (indicated by the open areas in Fig. 5), high specific power can be obtained with superconducting magnets and capacitors but only at relatively low specific energy. Higher specific energy levels are obtainable with batteries and flywheels but at lower specific power.

Crosshatched regions in Fig. 5 show the long term profections for the various storage options. If these projections are realized, then flywheels, fuel cells and batteries w11l become viable technologies. However, even with advances, capacitors and superconducting magnets do not appear viable storage options. The performance levels used in the value analysis, near term and advanced, are given in Table 2.

Nuciear Systém Analýsis

The nuclear system analysis used a Rankine concept with a lithiun-cooled reactor and potassium botler as the baseline systen. 9 Cycle colponent masses were based on literature values.10 Rankine cycle efficlency calculated by the model is $70 \%$ of Carnot, which is in reasonable agreement with the results of detailed cycle analysis.9 Details of the model are given in Ref. 10 .

Nuclear Rankine system masses with sprint power modules (at near term performance levels) were compared to the baseline nonstorage systen to determine the value of the storage component. As shown in Fig. 6, incorporation of a storage unit with the operating characteristics of the flywheel store reduces the total system mass significantly. The crossover point occurs at 500 seconds. For generation times on the order of 100 to 200 seconds, mass reductions are on the order of $65 \%$. As the generation time increases, the mass savings decrease. 
The horizontal (or near horizontal) lines in Fig. o indicate that the storage unit design is fixed by the power density of the unit. The curved lines indicate that the system performance is dominated by the storage density. The results in Fig. 6 , therefore, indicate that if batteries and fuel cells are to become viable candidates their power density must be increased. Capacitor and superconducting magnet storage systems, however, would require an increase in storage density. To extend the crossover point of the flywheel system will require an increase in storage density.

If long range performance levels are attained, batteries, fuel cells and flywheels can provide significant reductions in nuclear Rankine system mass. As shown in Fig. 7, advances in flywheel storage density result in the crossover time being extended to $750 \mathrm{~s}$. It is also apparent that the battery and flywheel systems yield essentially the same savings. Fuel cells, by virtue of their high specifjc energy, show a crossover point at about $1125 \mathrm{~s}$.

With multi-orbit charging, further reductions in the primary power system would be possible. The savings would be in direct proportion to the number of orbits allowed for recharging. However, the effect on overall system mass is not as great; because the storage unit accounts for about $80 \%$ of the total system mass and dominates the primary power system. Thus, if recharging took place over ten orbits, a mass reduction of $90 \%$ would occur in the primary power system. The mass of the total system would be reduced by $15 \%$ and the crossover point would be extended slightly. The greatest benefit to be derived is that a substantially smaller reactor system is required, and the reactor operates in a steady state mode as opposed to experiencing rapid changes in power output. It is anticipated that the development program for this smaller reactor may have fewer technical uncertainties than that for the larger pulsed reactor. With single orbit recharge, the nuclear system power rating would be on the order of 90 MWe to satisfy a 500 MWe sprint requirement. With recharge over 10 orbits, a reactor power on the order of $9 \mathrm{MWe}$ is required.

Solar System Analysis

In systems using solar input as the primary energy source, storage is required to insure operation during the eclipse portion of the orbit. Thermal storage can be used as the energy source for the power conversion system, replacing the solar input. Alternatively, regenerable storage modules can be charged during the insolation portion of the orbit and then used in place of the power conversion unit to supply power for sprint operation.

Both Brayton and Rankine power conversion cycles were considered. The Rankine cycle was identical to that used for the nuclear case. The Brayton cycle model ll accounts for turbine and compressor inefficiencies and different turbine and compressor ratios. Regenerative heat exchange is also included. The concentrator/receiver uses a pabolic concentrator with performance affected by slope and specularity errors, pointing accuracy, and blockage by the receiver. 12 
Power system analysis was performed to determine area and mass requirements. Concentrator areas for the two concepts were found to be on the order of $100,000 \mathrm{~m}^{2}$, which is excessively large. This pointed to the need for multi-orbit charging to reduce concentrator areas to reasonable values. The potential for area reductions in the solar Rankine system utilizing thermal storage is illustrated in Fig. 8. These results confirm that increasing the orbital recharge period by an order of magnitude yields a corresponding order of magnitude decrease in the concentrator area. Thus, to achieve concentrator areas on the order of $1000 \mathrm{~m}^{2}$ will require a charging period of about 100 orbits.

The solar analysis included consideration of TES and regenerable electrical storage modules (at the advanced performance levels). Thermal storage was included in the source and sink. Silicon-based alloys were used as the TES medium at the source. The storage densities were 1.2 and $1.5 \mathrm{MJ} / \mathrm{kg}$ for the Rankine and Brayton cycles, respectively. Sink storage for the Rankine cycle was accomplished using LiH. Because of the lower rejection temperature, the Brayton cycle used a salt with a storage density of $0.2 \mathrm{MJ} / \mathrm{kg}$. As indicated in Figs. 9 and 10 , regenerable storage modules are the preferred storage systems. The results show that for shorter generation times, the storage system having the highest specific power result in the minimum mass system. As the generation time is extended (in this case beyond $400 \mathrm{~s}$ ), the system having the highest storage density is favored.

It is interesting that the two minimum mass solar concepts have alnost identical masses. This is because the overall system mass is dominated by the storage system mass. Hence, differences "in the specific mass of the Rankine and Brayton power conversion systems are not major factors.

The comparison of solar and nuclear options (see Figs. 7, 9 and 10) indicates that the nuclear and solar systems capable of meeting the sprint need have the potential to be about equal in mass. The nuclear systen shows a slight advantage for short generation times, while the situation 18 reversed for longer generation times. For this to occur, however, requires that the solar recharge time be on the order of 100 orbits; while the nuclear system is recharged in only a single orbit. Again the masses are nearly identical because the storage system is the dominant mass component. Thus, differences in the primary power systen specific masses are not significant in comparisons of total system mass.

\section{SUMMARY}

The overall conclusions from the TES/heat rejection analyses are that inclusion of storage in the heat refection system is beneficial for generation times of significant length. The crossover time depends upon the radiator specific mass and the performance paraneters of the TES unit. With mitiple orbit recharge the crossover time approaches 1100 seconds." 
Evaluation of regenerable sprint power modules incorporated with nuclear Rankine primary power systems indicates that the storage system reduces system mass for generation periods of up to 1125 seconds. At near term performance levels, flywheels are the only viable storage option. With advances in storage technology, batteries, flywheels and fuel cells can all play a role in reducing overall system mass. An additional benefit of storage is that the required reactor is small (compared to that needed to produce at the sprint power level) and it does not experience the rapid power ramps required of the non-storage reactor.

Area requirements for solar systems using a single orbit for recharge were found to be excessive. Thus, multi-orbit charging was required. The solar analysis included TES (source and sink) and regenerable storage modules (at the advanced performance levels). The results indicate that flywheels, batteries, and fuel cells are viable options. Comparison of the solar results (using a 100-orbit recharge time) and the nuclear Rankine results (using a single orbit for recharge) indicated the systems had almost identical masses. This result occurs because the storage system is the dominant mass component for the overall system and all three systems employ the same storage technology.

\section{REFERENCES}

1. Barin, J., Knacke, 0., and Kubaschewski, 0., "Thernochenical Properties of Inorganic Substances: "Supplenent 1," SpringerVerlag, Berlin, 1977.

2. Stul1, D. R., and Prophet, H., compilers, "Joint Army-Navy-Air Force (JANAF) Property Tables," National Bureau of Standards, Washington, D.C., 1970; Supplement, 1974.

3. Morris, D. G., Foote, J. P., and Olszewski, M., "Development of Encapsulated Lithium Hydride Thermal Energy Storage for Space Power Systems," ORNL/TM-10413 (to be published).

4. Olszewski, M., "Development of Regenerable Energy Storage for Space Multimegawatt Applications," Proceedings "2lst Intersoctety Energy Conversion Engineering Conference, San Diego, CA, August 25-29, 1986, pp. 1838-1841.

5. Eyssa, Y. M., Boom, R. W., McIntosh, G. E. and LI, Q., "A 100 KWh Energy Storage Coll for Space Applications," IEEE Transactions on Magnetics, May 1983, Vo1. MAG-19, No. 3, Part II.

6. D. C. Fee, Argonne National Laboratory, personal communication with author, March 1987.

7. J. L. Preston, United Technologies Power Systems, personal commication with author, March 1987.

8. D. U. O'Kain, Martin Marietta Energy Systems, Inc., personal conmunication with author, March 1987. 
9. Moyers, J. C., "ALKACYCL, A Base Computer Program for the Analysis of Alkall Metal Rank1ne Power Cycles," ORNL/TM-9693, August 1985.

10. Morris, D. G., Hoffman, H. W., and Olszewsk1, M., "Energy Storage Concepts for Pulsed Space Power Cycle Annual Report for Period May 1985 - Juile 1986," (In publication as Air Force Wright Aeronautical Laboratory Report).

11. Sorensen, Harry A., Princlples of Thermodynamics, Holt, Rinehart, and Winston, April 1961.

12. Jaffe, L. D., "Optimization of Dish Solar Collectors With and W1 thout Secondary Concentrators," DOE/JPL-1060-57, May 1982.

* Research sponsored by the Office of Nuclear Energy under U.S. DOE contract No. DE-AC05-840R21400 with Mart1n Marietta Energy Systems, Inc.

The submitted manuscript has been authored by a contractor of the U.S. Government under contract No. DE-ACO5-840R21400. Accordingly, the U.S. Government retains a nonexclusive, royalty-free license to publish or reproduce the published form of this contribution, or allow other to do so for U.S. Government purposes. 
Table 1. Radiator Heat Flux and Storage Density With Varying Minimum Storage Temperature

\begin{tabular}{cccc}
$\begin{array}{c}\text { Storage Minimum } \\
\text { Temperature } \\
(\mathrm{K})\end{array}$ & $\begin{array}{c}\text { Average Radiator } \\
\text { Heat Flux } \\
\left(\mathrm{kW} / \mathrm{m}^{2}\right)\end{array}$ & $\begin{array}{c}\text { Specific Energy } \\
(\mathrm{MJ} / \mathrm{kg})\end{array}$ \\
\hline 300 & 5.5 & 7.90 & 5.76 \\
400 & 11.9 & 7.44 & 5.40 \\
500 & 19.2 & 6.96 & 5.04 \\
600 & 26.9 & 6.42 & 4.62 \\
700 & 34.5 & 5.80 & $\ldots .16$ \\
\hline
\end{tabular}


Table 2. Performance Levels for Storage Technologies Applicable to Regenerable Storage Modules

\begin{tabular}{lccccc}
\hline & \multicolumn{2}{c}{ Near Term } & \multicolumn{2}{c}{ Advanced } \\
\cline { 2 - 3 } \cline { 5 - 6 } Technology & $\begin{array}{c}\text { Specific Energy } \\
(\mathrm{kJ} / \mathrm{kg})\end{array}$ & $\begin{array}{c}\text { Specific Power } \\
(\mathrm{kW} / \mathrm{kg})\end{array}$ & $\begin{array}{c}\text { Specific Energy } \\
(\mathrm{kJ} / \mathrm{kg})\end{array}$ & $\begin{array}{c}\text { Specific Power } \\
(\mathrm{kH} / \mathrm{kg})\end{array}$ \\
\hline Flywheel & 360 & 2.5 & 600 & 3.5 \\
Fuel Cell & 54 & 0.1 & 1000 & 1.6 \\
Battery & 200 & 0.30 & 600 & 2.0 \\
SilES & 55 & 1000 & NA & NA \\
Capacitor & 30 & 8000 & NA & NA \\
\hline
\end{tabular}




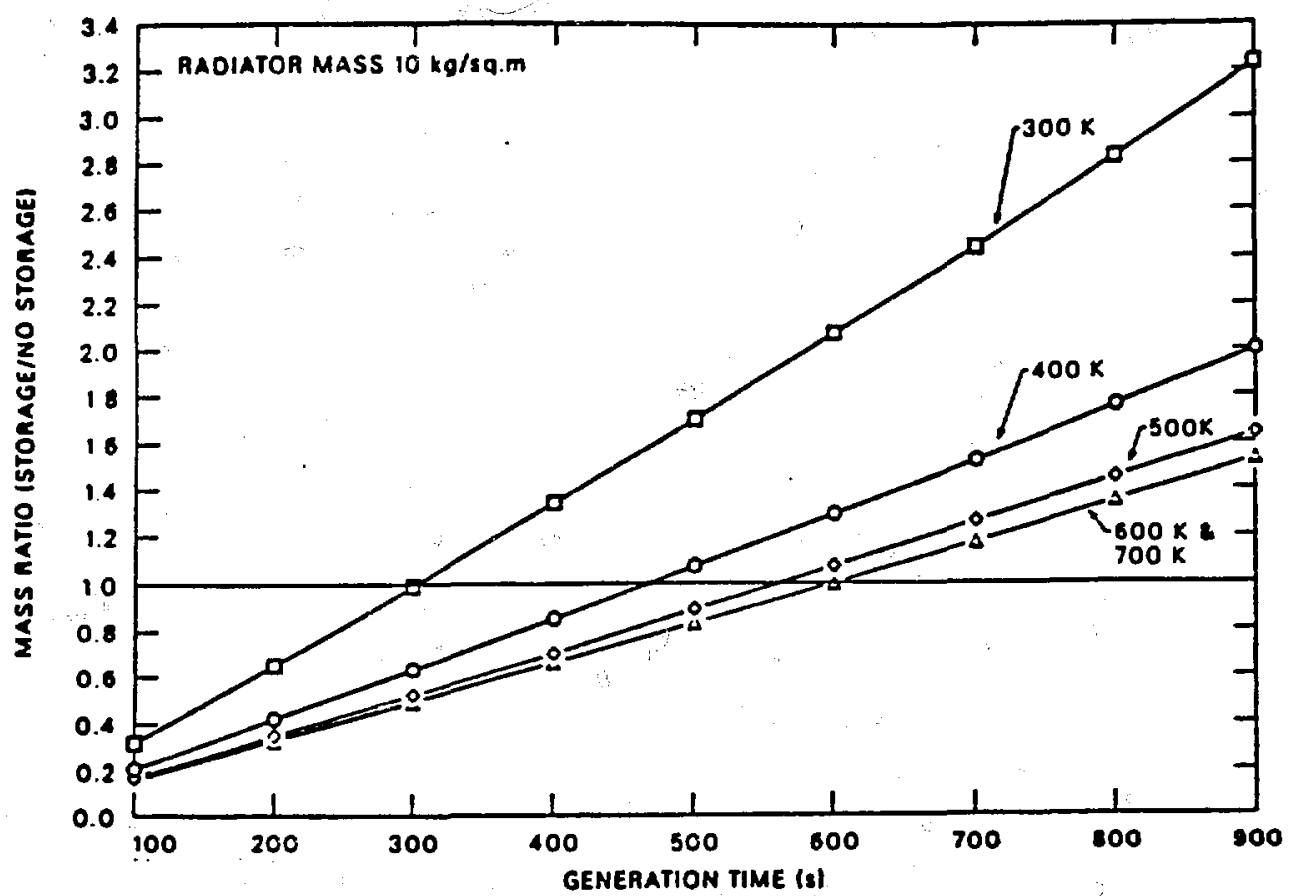
System.

F1g. 1. Heat Rejection System Mass Ratio for Direct Contact

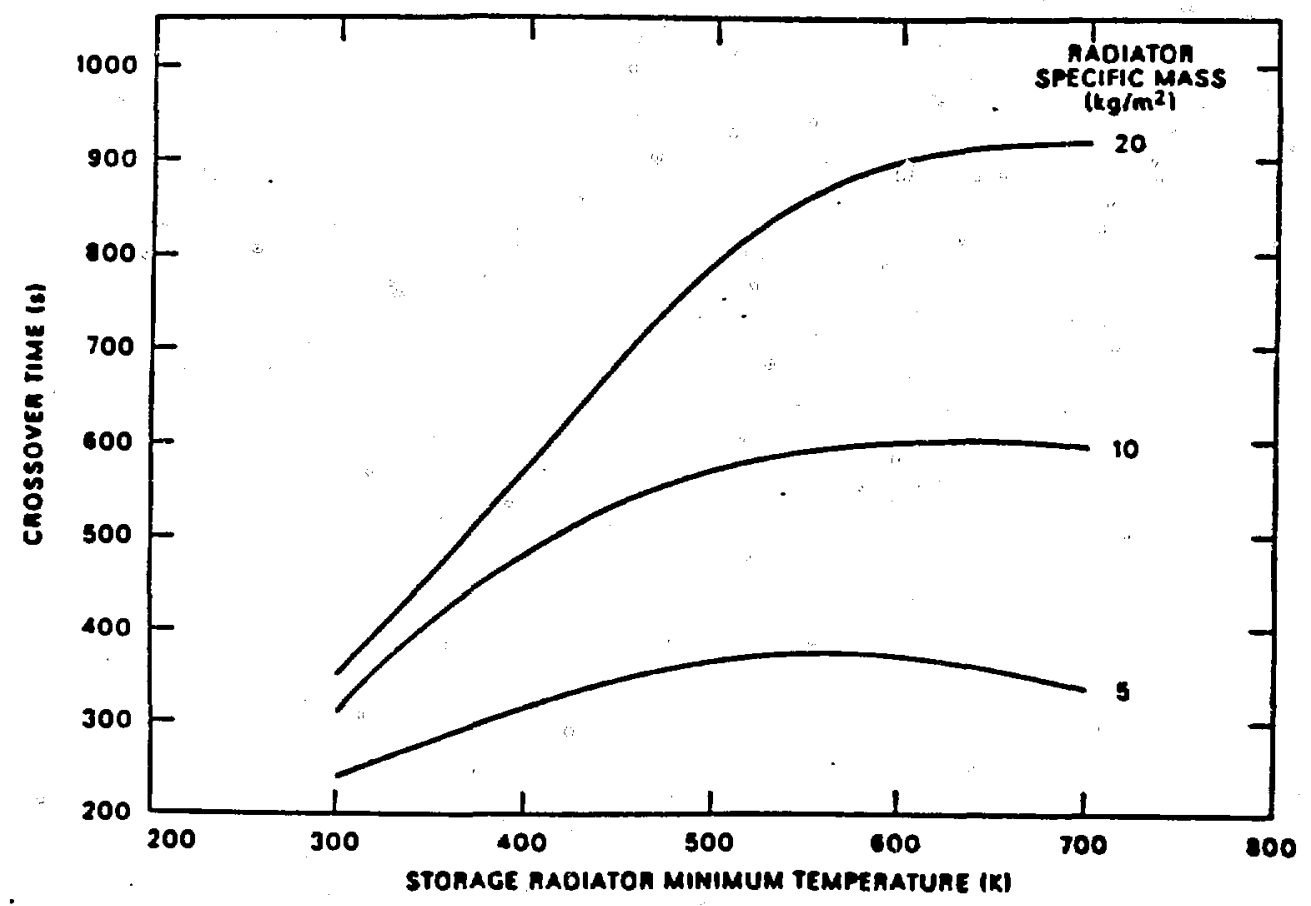

F1g. 2. Parametric Evaluation of Heat Refection Systen Masa Crosaover Tine for Direct Contact System. 

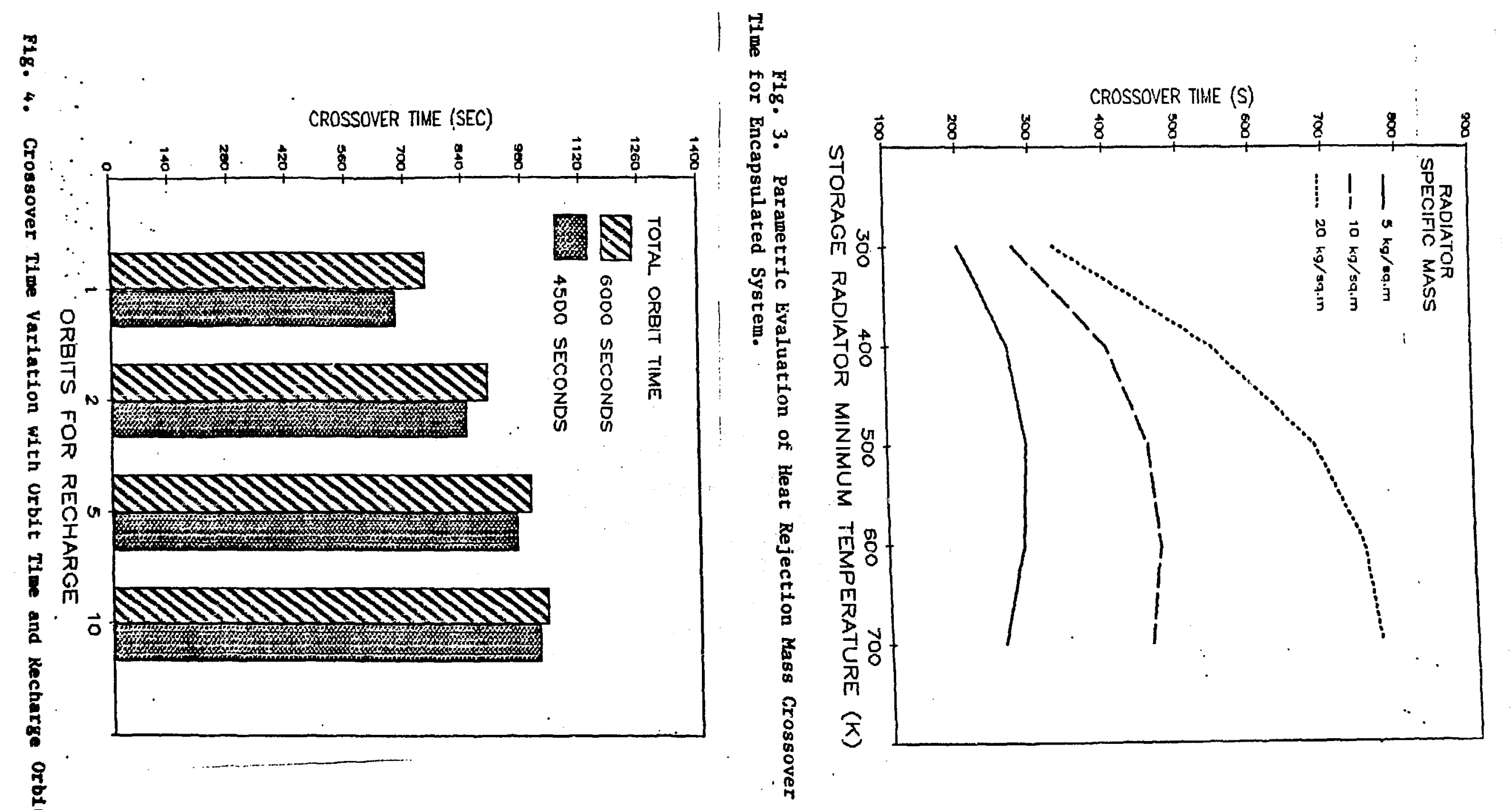


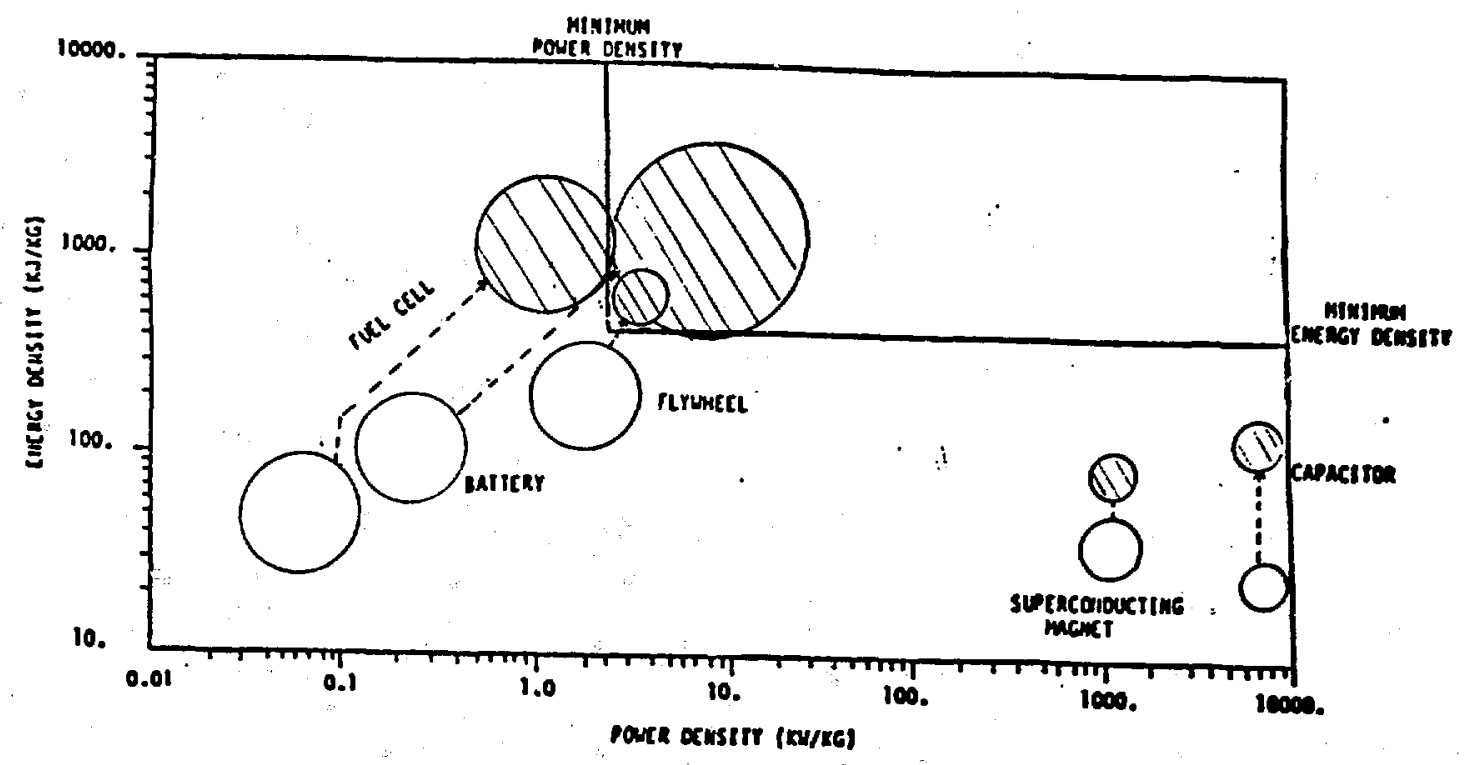
Levels.

F1g. 5. Sprint Power Energy Storage Module Near Term and Advanced

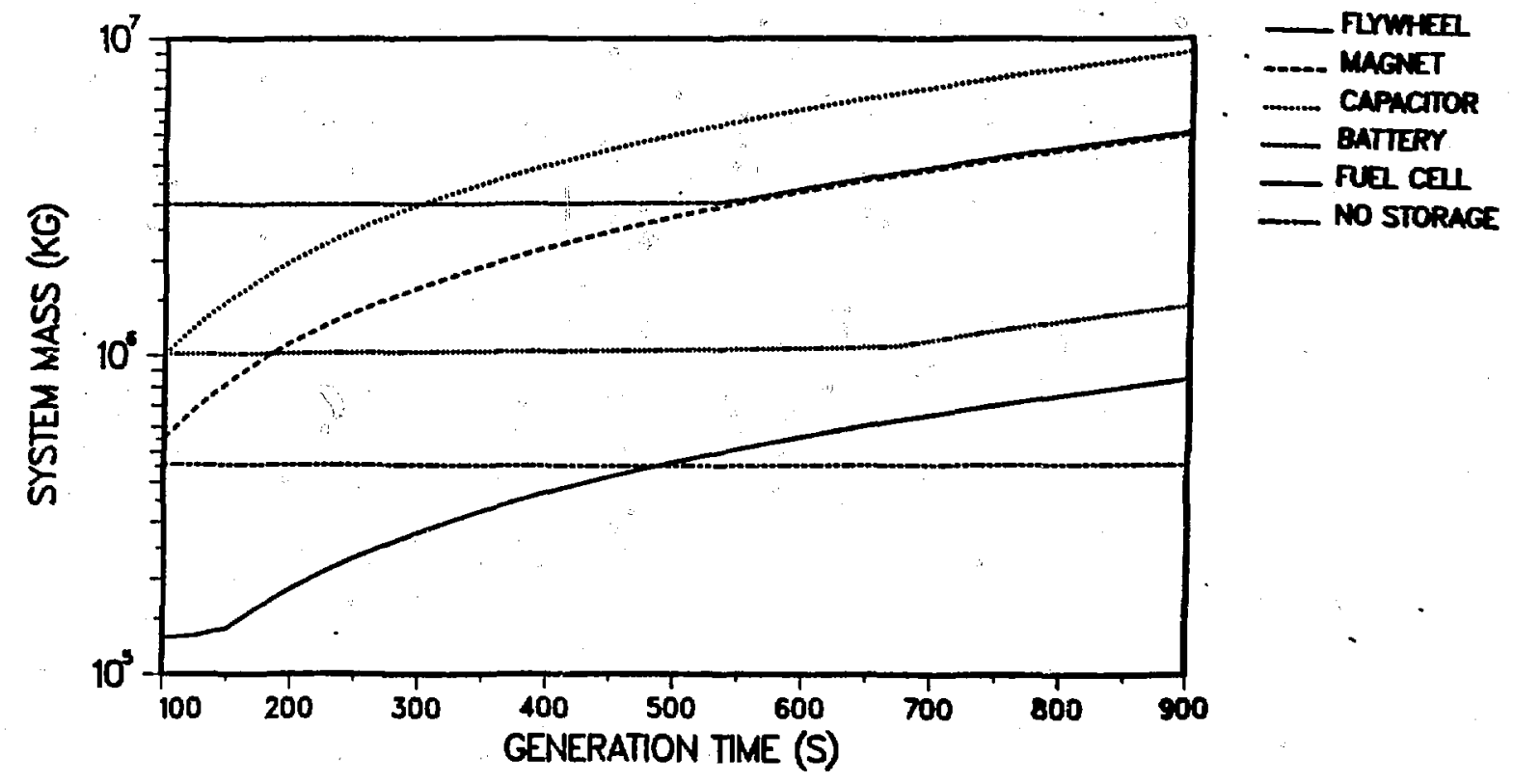

F1g. 6. Effect of Storage at Current Technology Levels on Nuclear
Ine Systen Mas. 


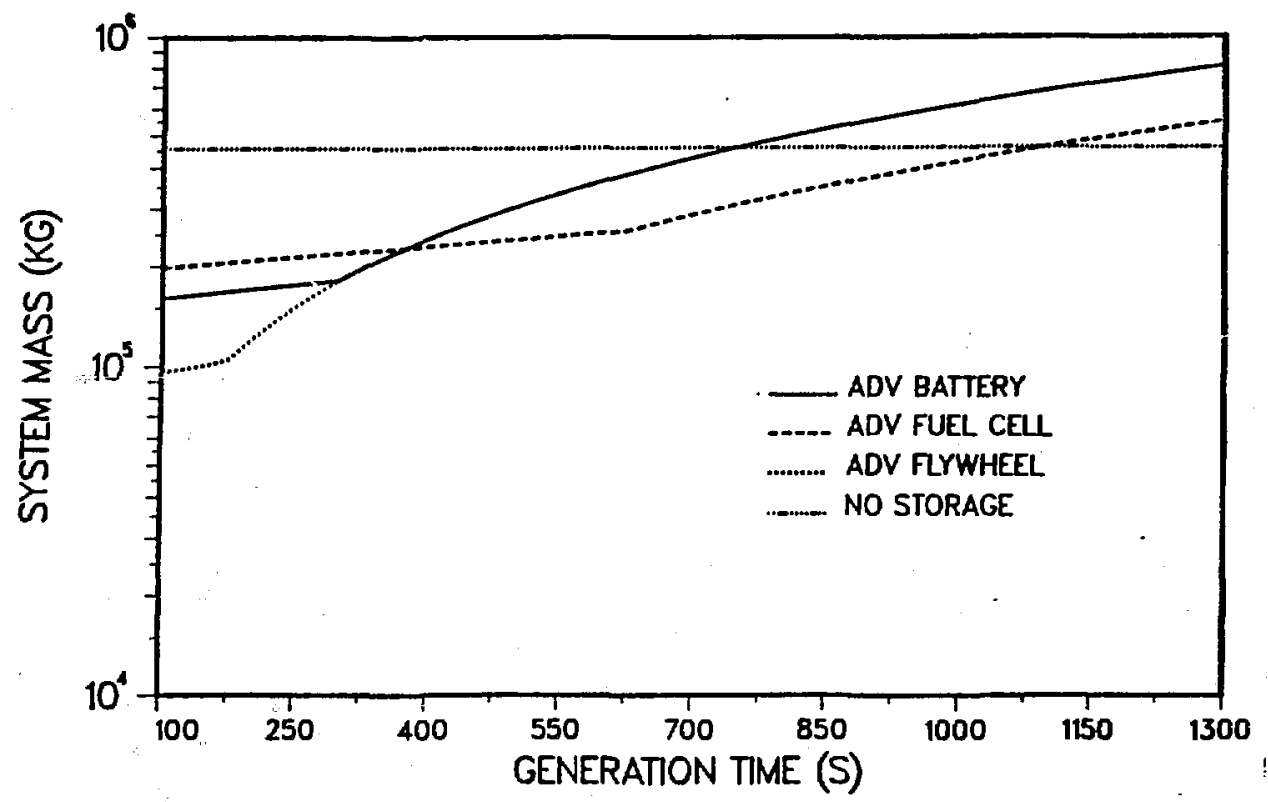

Fig. 7. Effect of Storage at Advanced Performance Levels on Nuclear Rankine System Mass.

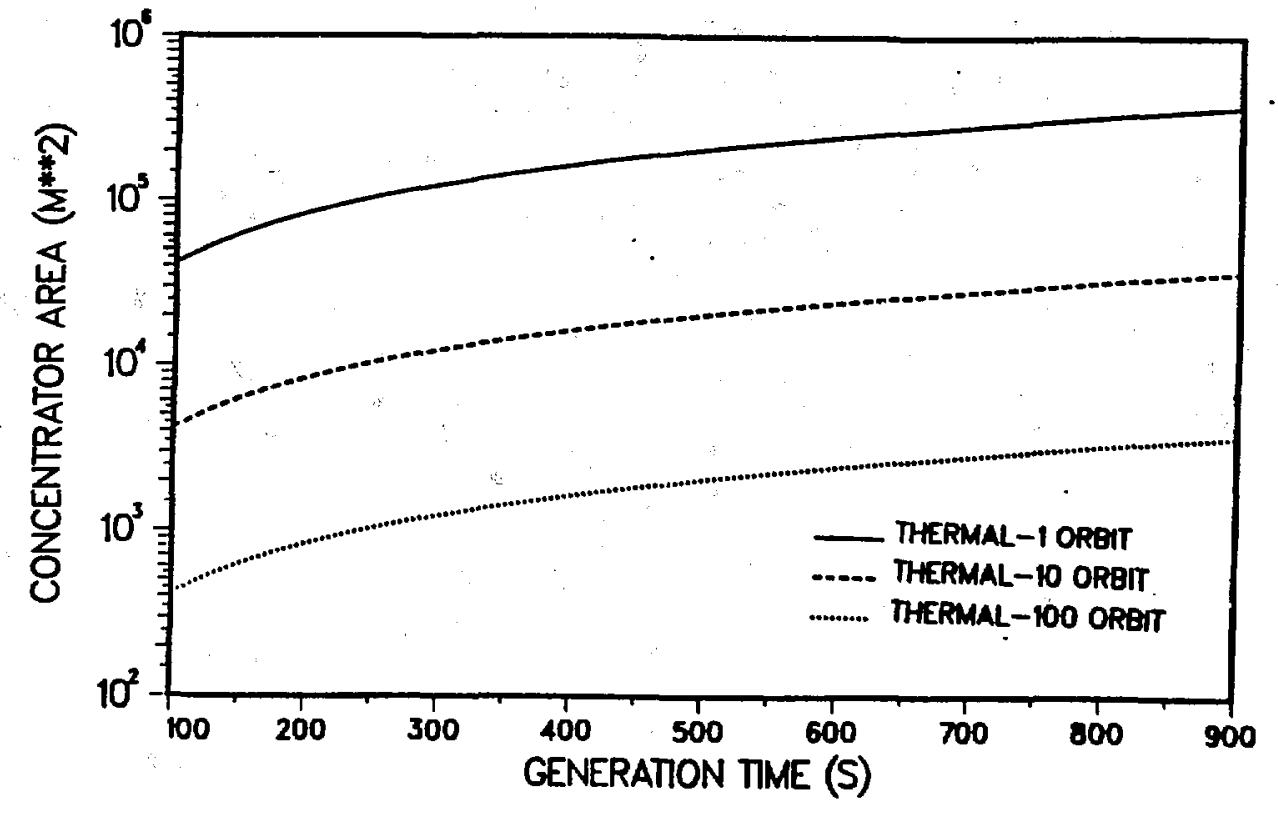

Fig. 8. Concentrator Area Variation with Recharge Orbits in Solar Rankine System. 


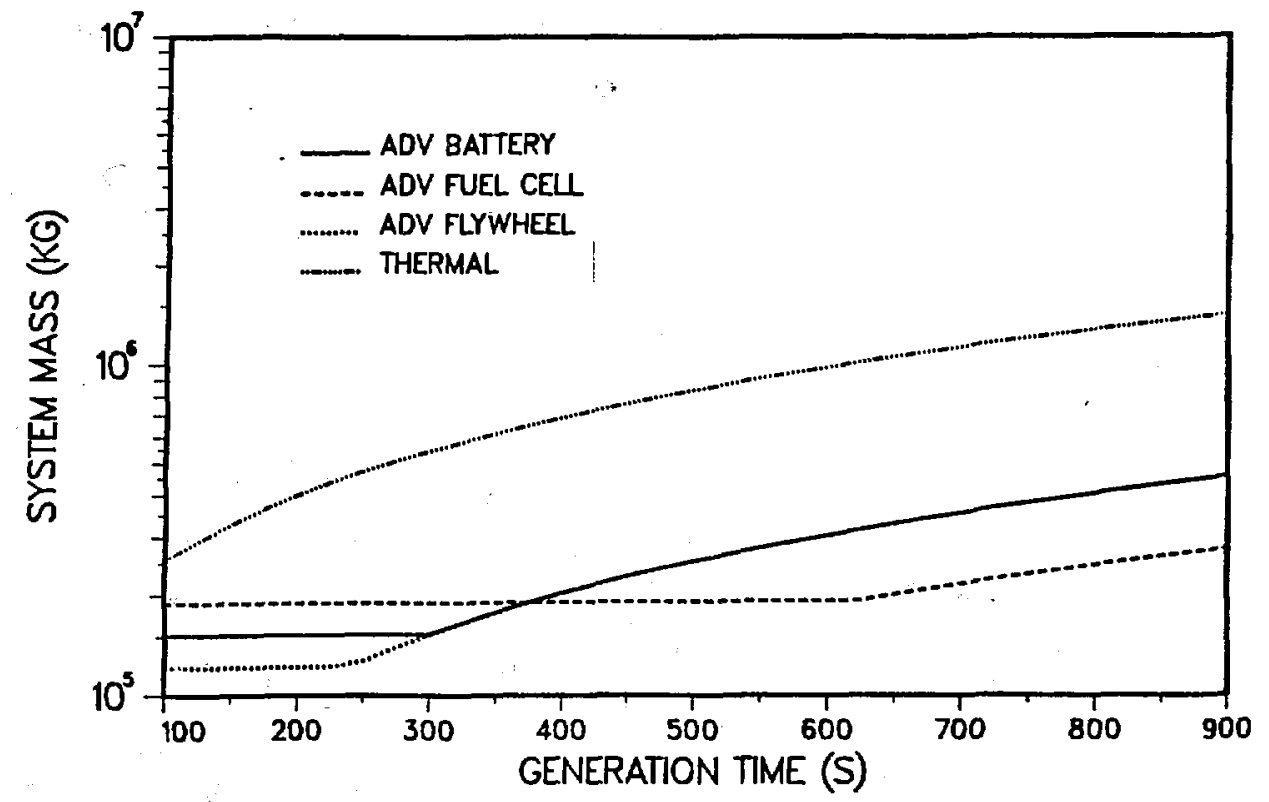

Fig. 9. Solar Rankine System Mass With Storage and 100 orbit Charge/Discharge.

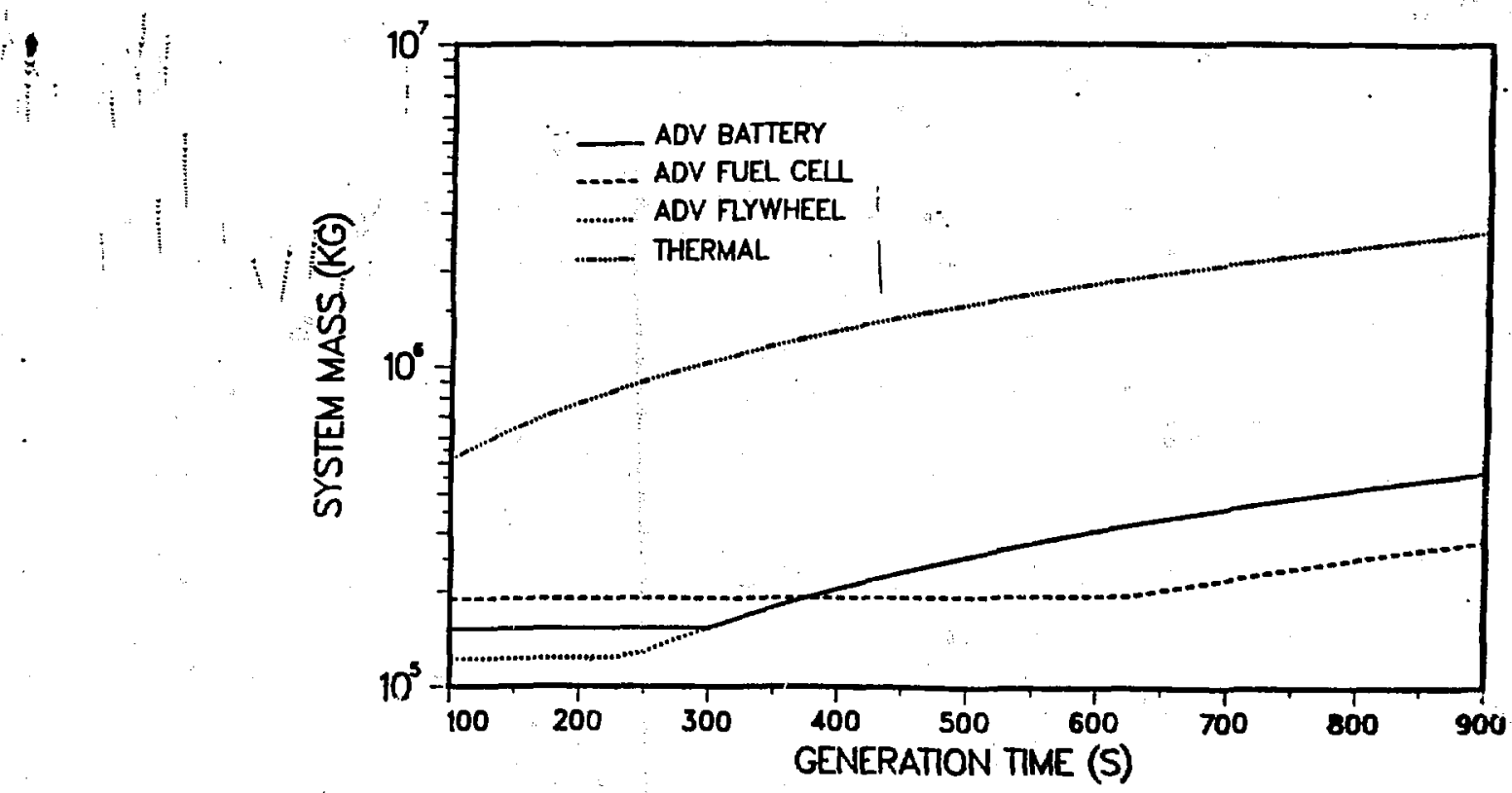

Fig. 10. Solar Brayton System Nass With Storage and 100 Orbit Charge/Discharge. 